\title{
Somatostatin receptor expression in hepatocellular carcinoma: prognostic and therapeutic considerations
}

\author{
Omar Abdel-Rahman, Angela Lamarca', Juan W Valle ${ }^{1,2}$ and Richard A Hubner ${ }^{1}$ \\ Clinical Oncology Department, Faculty of Medicine, Ain Shams University, Cairo, Egypt \\ ${ }^{1}$ Department of Medical Oncology, The Christie NHS Foundation Trust, Wilmslow Road, Manchester M20 4BX, UK \\ ${ }^{2}$ University of Manchester, Manchester Academic Health Sciences Centre (MAHSC), Manchester, UK
}

\author{
Correspondence \\ should be addressed \\ to R A Hubner \\ Email \\ richard.hubner@christie. \\ nhs.uk
}

\begin{abstract}
Sorafenib is the only systemic therapy to demonstrate a significant survival benefit over supportive care in robust randomised controlled trials for advanced hepatocellular carcinoma (HCC). In the context of an intense search for prognostic and predictive factors for response and efficacy of different systemic therapies (including sorafenib), a number of molecular targets have been identified, paving new avenues for potential therapeutic opportunities. Such molecular targets include somatostatin receptor (SSTR)-related alterations. In this review, we provide an overview of the various considerations relating to SSTRs as potentially novel prognostic and predictive biomarkers for HCC with special emphasis on the therapeutic potential of somatostatin analogues in HCC management.
\end{abstract}

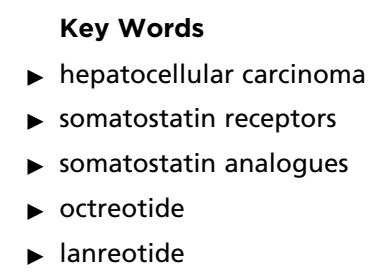

Endocrine-Related Cancer (2014) 21, R485-R493

\section{Introduction}

Hepatocellular carcinoma (HCC) is a global health problem as it is the sixth most common cancer in the world and the third leading cause of cancer-related death. The incidence of HCC shows wide geographical variation with Western countries having an annual incidence of $\sim 3$ per 100000 , rising to 15 per 100000 in parts of Africa and Asia (Parkin et al. 2005). This variation closely mirrors the geographical distribution of viral hepatitis B (HBV) and hepatitis C (HCV), the most important causes of chronic liver disease and HCC (Kim \& Han 2012).

Multiple classification schemes have been suggested for this aggressive disease; the most commonly implemented system has been the Barcelona Clinic Liver Cancer (BCLC) system, which is characterised by integrating disease-related factors as well as patient-related factors (Child-Pugh classification and performance status assessment) in one unified system (Song \& Bae 2012). The BCLC classification scheme has been adopted globally and has significantly influenced many national and international guidelines (Park et al. 2013).

Many patients with HCC present with advanced disease (BCLC C) that is not suitable for loco-regional therapies (such as resection, transplantation, radio frequency ablation or transarterial therapies) due to either the high burden of liver disease, extra-hepatic spread or poor performance status related to cirrhosis. Such patients may be candidates for palliative systemic therapies.

Sorafenib, an orally available, multi-tyrosine kinase inhibitor, is the only systemic therapy to demonstrate significant survival benefit over supportive care in the context of two robust randomised controlled trials (Llovet et al. 2008, Cheng et al. 2009). However, a lack of prognostic

Published by Bioscientifica Ltd. 
and predictive biomarkers has hindered the proper tailoring and personalisation of sorafenib treatment. This has stimulated an ongoing intensive search for prognostic and predictive factors for response and efficacy of different systemic therapies in HCC (including sorafenib), and a number of molecular targets have been identified paving new avenues for potential therapeutic opportunities. Such molecular targets include MAP kinase pathway alterations (Galuppo et al. 2014), vascular endothelial growth factor (VEGF) pathway alterations (Chen et al. 2014), as well as somatostatin receptor (SSTR)-related alterations.

In this review, we provide an overview of the various considerations relating to SSTRs as potentially novel prognostic and predictive biomarkers for HCC.

\section{Biology of somatostatin and SSTRs}

Somatostatin (SST) was first described in 1968 as a hormone secretion inhibitor molecule (Krulich et al. 1968) and was later found to be coded by a unique human gene (SST) on the short arm of chromosome 3 . The SST protein has two active forms produced by alternative cleavage of a single pre-protein: one of 14 amino acids (SST14) and the other of 28 amino acids (SST28), which differ in their potency rather than in their function (see Table 1) (Benoit et al. 1990).

Secretion of SST in the hypothalamus results in inhibition of important hormones such as growth hormone (GH), thyroid-stimulating hormone (TSH), and prolactin (PRL). While in the gastrointestinal tract, SST secretion controls gastric acid production and also inhibits the release of other hormones such as gastrin, cholecystokinin, glucagon, secretin, vasoactive intestinal peptide (VIP), gastric inhibitory polypeptide (GIP) and insulin. SST can also decrease gastrointestinal motility and gallbladder contraction by reducing blood flow and inhibit exocrine pancreatic secretion (Lamberts et al. 1996).

Five SSTR subtypes have been characterised: SSTR1, SSTR2, SSTR3, SSTR4 and SSTR5. All SSTRs have capability to bind natural SST14 and SST28 with a high affinity, while there is a significant variation in binding of synthetic SST peptides or somatostatin analogues (SSAs) (Barbieri et al. 2013) (see Table 1).

SSTRs are inhibitory G protein-coupled receptors that are ubiquitously expressed in normal tissues and cancer. They are located in the cellular membrane with seven membrane-spanning domains and are coupled to transmembrane calcium and potassium ion channels, and intracellular enzymes including adenylate cyclase (ACL) and phosphotyrosine phosphatases (PTPs) such as Src homology phosphatase 1 (SHP1), Src homology phosphatase 2 (SHP2) and phosphotyrosine phosphatase $\eta$ (РTP $\eta$ ). Upon binding of SST or SSAs, SSTRs activate intracellular pathways that result in anti-secretory effect (Fig. 1A), inhibition of proliferation (Fig. 1B) and apoptosis (Fig. 1C) (Lamberts et al. 1996, Dasgupta 2004, Barbieri et al. 2013). An anti-angiogenic effect of SST and SSAs has also been described, which seems to be related to paracrine inhibition

Table 1 Five somatostatin receptors (SSTRs) have been identified; each SSTR is detailed in this table together with its expression in normal tissue and its capability to bind either natural SST (SST14 and SST28) or synthetic somatostatin analogues (SSAs) such as octreotide, lanreotide or pasireotide. Data from Lamberts et al. 1996, Barbieri et al. 2013.

\begin{tabular}{|c|c|c|c|c|c|}
\hline Receptor & SSTR1 & SSTR2 & SSTR3 & SSTR4 & SSTR5 \\
\hline $\begin{array}{l}\text { Expression (non- } \\
\text { tumoural tissue) }\end{array}$ & $\begin{array}{l}\text { Brain, lungs, stomach, } \\
\text { jejunum, kidneys, } \\
\text { liver and pancreas }\end{array}$ & $\begin{array}{l}\text { Brain, jejunum, colon, } \\
\text { pancreas ( } \alpha \text { cells) } \\
\text { liver and adrenals } \\
\text { (cortex and } \\
\text { medulla) }\end{array}$ & $\begin{array}{l}\text { Brain, thyroid } \\
\text { and pancreas }\end{array}$ & $\begin{array}{l}\text { Brain and } \\
\text { lungs }\end{array}$ & $\begin{array}{l}\text { Brain, heart, adrenal } \\
\text { gland, thyroid, } \\
\text { placenta, pituitary, } \\
\text { small intestine, skeletal } \\
\text { muscle and pancreas } \\
\text { ( } \beta \text { cells) }\end{array}$ \\
\hline $\begin{array}{l}\text { Binding affinity by } \\
\text { SST14 }\left(\mathrm{IC}_{50} \mathrm{nM}\right)\end{array}$ & Yes $(0.1-2.26)$ & Yes $(0.2-1.3)$ & Yes (0.3-1.6) & Yes (0.3-1.8) & Yes $(0.2-0.9)$ \\
\hline $\begin{array}{l}\text { Binding affinity by } \\
\text { SST28 (IC } 50 \mathrm{nM})\end{array}$ & Yes (0.1-2.2) & Yes $(0.2-4.1)$ & Yes $(0.3-6.1)$ & Yes (0.3-7.2) & Yes $(0.05-0.4)$ \\
\hline $\begin{array}{l}\text { Binding affinity by } \\
\text { Octreotide }\left(\mathrm{IC}_{50} \mathrm{nM}\right)\end{array}$ & No $(>1000)$ & Yes (0.4-2.1) & No (4.4-34.5) & No $(>1000)$ & Yes (5.6-32) \\
\hline $\begin{array}{l}\text { Binding affinity by } \\
\text { Lanreotide }\left(\mathrm{IC}_{50} \mathrm{nM}\right)\end{array}$ & No $(>1000)$ & Yes $(0.5-1.8)$ & No (43-107) & No $(>1000)$ & Yes (0.6-14) \\
\hline $\begin{array}{l}\text { Binding affinity by } \\
\text { Pasireotide }\left(\mathrm{IC}_{50} \mathrm{nM}\right)\end{array}$ & Yes (9.3) & Yes (1) & Yes (1.5) & No $(>100)$ & Yes $(0.16)$ \\
\hline
\end{tabular}
$\mathrm{IC}_{50} \mathrm{nM}$ : half maximal inhibitory concentration $\left(\mathrm{IC}_{50}\right.$ represents the concentration of a drug that is required for $50 \%$ inhibition in vitro; the lower the $\mathrm{IC} \mathrm{C}_{50}$ 
of the excretion of pro-angiogenic molecules such as VEGF and insulin growth factor (IGF) via ACL inhibition (Fig. 1A) (Garcia de la Torre et al. 2002, Ristori et al. 2008).

\section{SSTRs and solid tumours}

During the last two decades, the pro-apoptotic, antiangiogenic and anti-proliferative effects of SSTR activation (see Fig. 1 for more detail) have been investigated in multiple translational and clinical research studies with the aim of developing new therapeutic options for solid malignancies. The large majority of these studies have failed to show a clinically relevant anti-tumour effect, most probably due to the co-existence of other activated pathways driving oncogenesis (Hejna et al. 2002, Keskin \& Yalcin 2013). The best examples of this failure are two randomised phase II trials investigating SSA therapy in patients with advanced breast cancer, both of which reported no benefit in progression-free survival (PFS) (Ingle et al. 1999, Bajetta et al. 2002). Similarly, a phase III randomised study in 260 patients with advanced colorectal cancer did not identify a benefit in survival (neither in time to progression nor in overall survival (OS)) in the SSA arm (Goldberg et al. 1995).

By contrast, an anti-tumour effect of SSA therapy has been demonstrated in advanced neuroendocrine tumours (NETs) in two large randomised studies both reporting significant and clinically relevant benefits: the PROMID (Rinke et al. 2009) and CLARINET (Caplin 2014) trials.

Currently, advanced NETs are the only clinical setting where SSAs can be employed for tumour control outside a clinical trial.

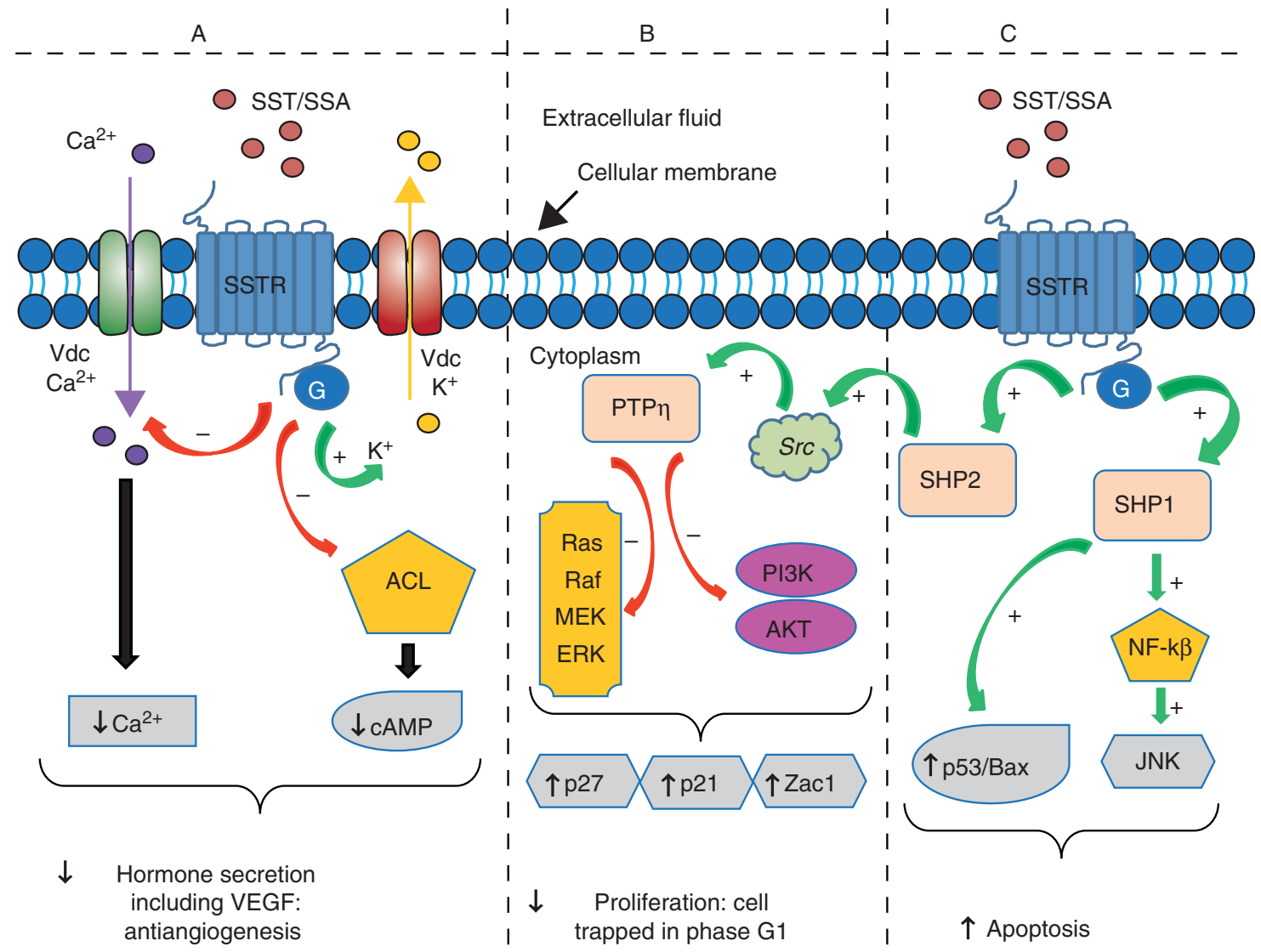

\section{Figure 1}

Schematic of the SSTR and its downstream activation of secretion and anti-angiogenesis. SSTR, somatostatin receptor; SST, somatostatin; SSAs, somatostatin analogues; Vdc, voltage-dependent channel; $\mathrm{Ca}^{2+}$, calcium; $\mathrm{K}^{+}$, potassium; $\mathrm{G}$, $\mathrm{G}$ protein; $\mathrm{ACL}$, adenylate cyclase; VEGF, vascular endothelial growth factor; Src, Rous sarcoma oncogene; SHP1, SrC homology phosphatase 1; SHP2, Src homology phosphatase 2; PTP $\eta$, phosphotyrosine phosphatase $\eta$; ras, RAS kinase; raf, rapidly accelerated fibrosarcoma kinase; MEK, mitogen-activated protein kinase kinase; PI3K, phosphoinositide 3 kinase; AKT, protein kinase $B$; Zac1, zinc finger protein regulator of apoptosis and cell cycle arrest; $p$, protein; NFKB, nuclear factor kappa B; BAX, B-cell lymphoma 2 (BCL2)-associated X protein; JNK, c-Jun $\mathrm{N}$-terminal kinases; $\uparrow$, increase; +/green arrows, activation; $\downarrow$, decrease; $-/$ red arrows, inhibition. 


\section{Prognostic and predictive values of SSTR expression in HCC}

HCCs display differential immunohistochemical (IHC) expression profiles for SSTRs; for example, in a study by Blaker et al. (2004), the overall expression rates of different subtypes (SSTR1, SSTR2, SSTR3, SSTR4 and SSTR5) in 56 specimens obtained from liver resection or transplantation were 46, 41, 64, 0 and 75\% respectively. Higher expression of SSTR2 (67\%) was shown by Verhoef et al. (2008), who were unable to correlate this expression with any other clinical or molecular characteristics including DNA ploidy status, Ki67 staining and tumour suppressor gene expression such as p16 (CDKN2A), p53 (TP53) and RB1. Moreover, Koc et al. (2013) reported positive expression of SSTR1 and SSTR5 by IHC in, respectively, 76 and $51 \%$ of needle biopsy samples from 41 patients diagnosed with HCC. Thus, the available literature indicates variable expression of SSTR subtypes in HCC. This may be related to non-standardisation of the methodology for measurement of SSTRs, differential SSTR expression among different stages of HCC or differences in the molecular biology of different aetiological and pathological subtypes of HCC. Nevertheless, SSTRs are expressed by a clinically meaningful proportion of HCC and may therefore be potential therapeutic targets.

Consequently, a number of preclinical and clinical studies have evaluated the potential prognostic value of SSTR expression profiles in HCC. For example, in a study by Li et al. (2012), specimens from 76 patients with operable HCC were evaluated. Down-regulation of SSTR transcription was found to result in a loss of a tumoursuppressive mechanism, thus characterisation of SSTR expression may identify a more aggressive disease and hence be a useful prognostic parameter in HCC.

Other studies have evaluated the predictive influence of SSTR expression in HCC patients treated with SSAs. In one study (Liu et al. 2013), expression of SSTR2 and SSTR5 mRNA was evaluated in 99 patients with early-stage hepatitis B virus (HBV)-related HCC who were treated with octreotide LAR following surgery; 47 patients were classified as 'high expression' and 52 patients 'low expression'. The tumour recurrence rate was significantly lower in the high-expression group compared with that of the low-expression group ( 64 vs $83 \% ; P=0.033$ ). Additionally, the median disease-free survival was 6.6 years (95\% CI $5.2-8.0)$ in the high-expression group and 3.4 years (95\% CI 2.5-4.3) in the low-expression group. Additionally, Borbath et al. (2012) have reported on a case of metastatic HCC with SSTR2 overexpression showing partial regression and more than 3 years of PFS on lanreotide treatment. However, consensus on the value of SSTR expression as a predictive biomarker in HCC has not been reached and needs to be further assessed in prospective studies. Moreover, the prognostic and predictive influences of SSTR expression have not been evaluated in the setting of novel systemic anti-angiogenic therapies such as sorafenib.

\section{Preclinical experience with SSTR-targeted therapeutics in HCC}

Multiple preclinical studies, most of them in HCC cell lines, have shown an anti-proliferative effect with both human SST (Chou et al. 1987) and SSAs (Chen et al. 2001 and Liu et al. 2004). In addition, Reynaert et al. (2004) demonstrated a significant reduction in the invasive capabilities in those HCC cell lines (HepG2 and HuH7) that were treated with SSA targeting SSTR1. The anti-proliferative effect of SSA has also been analysed in vivo, mainly with nude mice xenografts. Hua et al. (2005) showed an inhibition of the growth of HCC in mice treated with octreotide, compared with controls, and up-regulation of SSTR2 expression and down-regulation of cMET expression. Mice xenografts have also demonstrated an inhibitory influence of SSAs on metastatic spread potentially related to an anti-angiogenic effect of SSAs (Jia et al. 2009). These preclinical data indicating potential anti-proliferative and anti-metastatic influences of SSAs in HCC supported the initiation of clinical studies in patients with HCC.

\section{Clinical experience with SSTR-targeted therapeutics in HCC}

A number of different retrospective and prospective studies have been conducted in the last two decades to evaluate the effects of SSAs, particularly octreotide, in advanced HCC (Table 2). However, the results in the majority of unselected patient populations were discouraging. For example, Barbare et al. reported a phase III study conducted in France evaluating long-acting octreotide vs placebo in 272 patients with HCC who were ineligible for curative treatments or had relapsed following potentially curative therapies. At the time of the final analysis, the median OS was 6.53 months (95\% CI 4.8-8.3) for octreotide vs 7.03 months (95\% CI 5.43-8.53) for placebo $(P=0.34)$. No objective responses were achieved in the octreotide group but 33\% of patients achieved disease stabilisation for a mean time of 5.5 months (95\% CI 1.19.9), although there was no significant difference in PFS compared with placebo. Thus, it has been concluded that,

Published by Bioscientifica Ltd. 


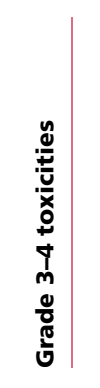

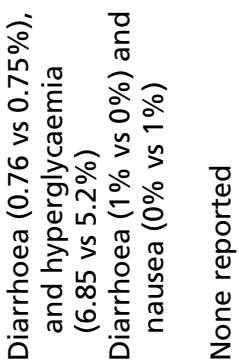
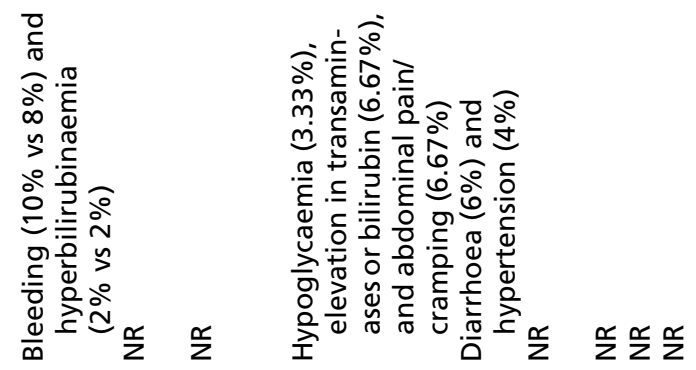

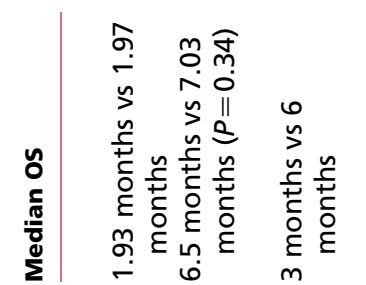

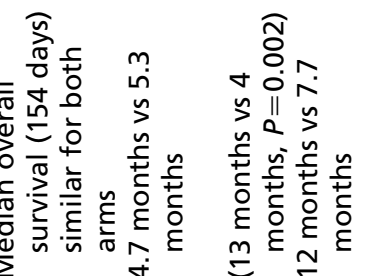

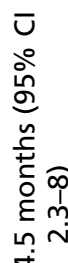

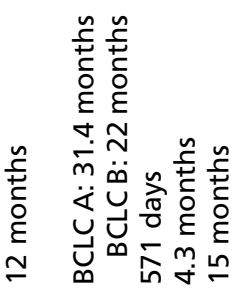

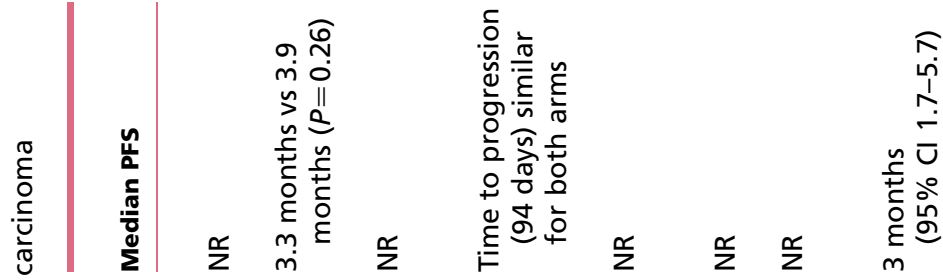
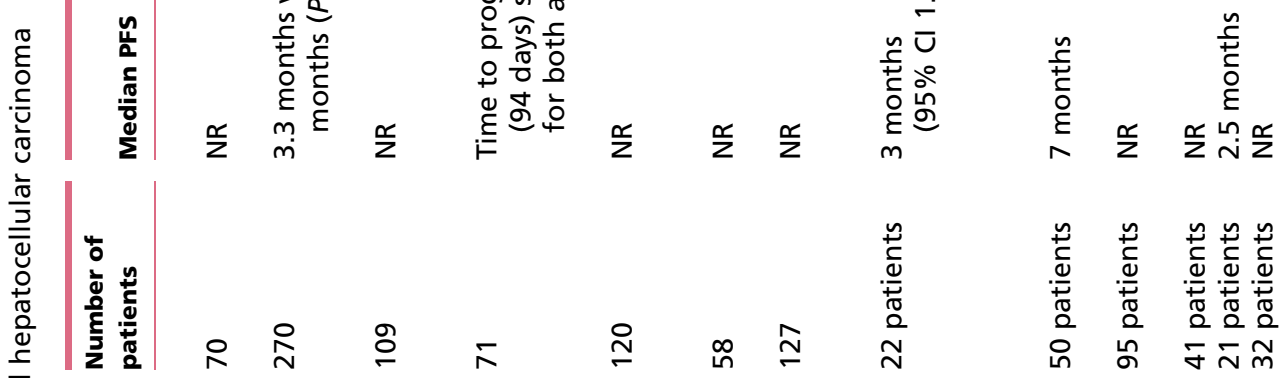

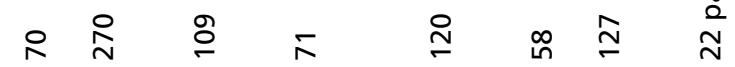

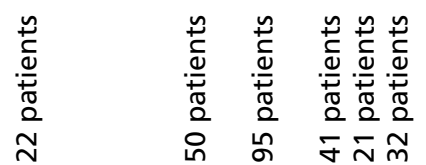

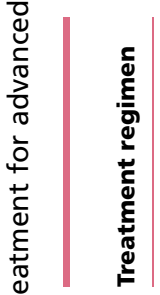
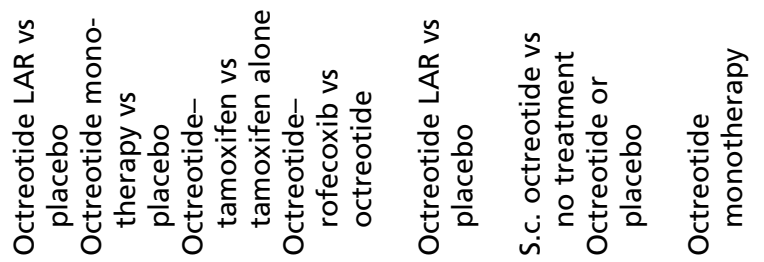

in ถู $\sigma \bar{N} \tilde{m}$

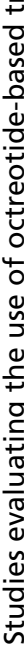

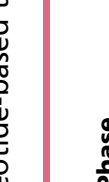

迹

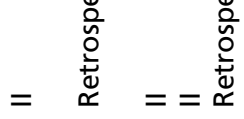

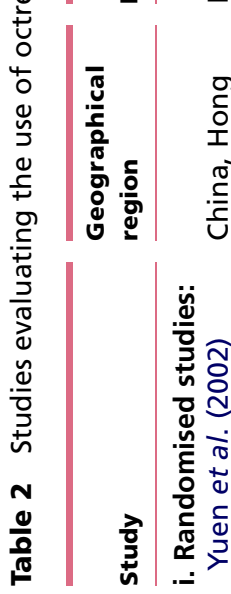

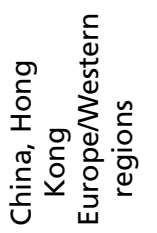

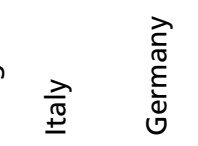

胥

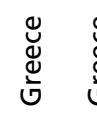

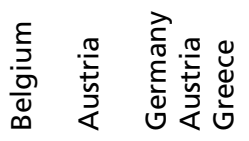

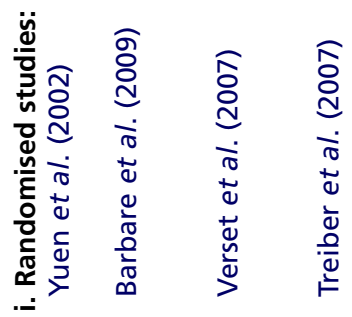

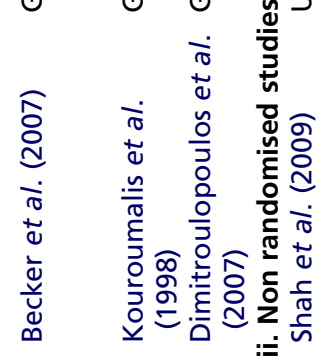

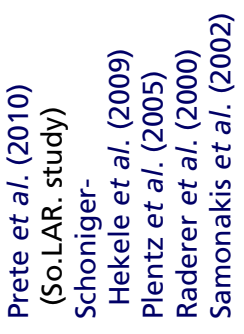


despite the favourable safety profile, octreotide had limited efficacy in patients with advanced HCC and led to no survival benefit. However, there were no data concerning SSTR expression and survival in this study.

Another phase III study conducted in Belgium evaluated the efficacy of tamoxifen (TMX) alone or in combination with long-acting release octreotide in 109 patients with advanced HCC. The median survival was 3 months (95\% CI 1.4-4.6) for patients receiving combination therapy and 6 months (95\% CI 2-10) for those receiving TMX alone $(P=0.609)$. There was no difference in terms of $\alpha$-fetoprotein ( $\alpha$-FP) decrease, tumour regression, improvement of quality of life or prevention of variceal bleeding between the two groups (Verset et al. 2007).

A multicentre phase II study evaluating the combination of sorafenib plus octreotide in advanced HCC (the So.LAR study) has been conducted in Italy; 50 patients with advanced HCC and Child-Pugh score A or B were included and administered sorafenib $800 \mathrm{mg} /$ day for 28 days with a following week of rest and long-acting octreotide at a dose of $40 \mathrm{mg}$ administered every 28 days. Out of 50 patients, 16 (34\%) were treatment naïve, while all others had previously received local and/or systemic treatments. Five partial responses were noted (10\%), 33 patients had stable disease $(66 \%)$ and 12 patients disease progression (24\%). The median time to progression was 7.0 months (95\% CI 3.0-10.9 months), and the median OS was 12 months (95\% CI 6.3-17.4 months). Treatment was well tolerated; diarrhoea (6\%) and hypertension (4\%) were the most frequent grade 3 toxicities (Prete et al. 2010).

The use of SSAs in advanced HCC has been evaluated in a meta-analysis conducted by Ji et al.: 11 randomised controlled trials including 802 patients were assessed and nine studies were included in the meta-analysis. The control group for studies included in the analysis was supportive care in seven studies and placebo in four studies. A pooled analysis of the four trials performed in Western countries indicated no significant differences in 6-month, 12-month, or 24-month OS rates between the octreotide group and the control group (6-month, relative risk (RR) 1.27, 95\% CI 0.96$1.67, P=0.09 ; 12$-month, RR $1.69,95 \%$ CI $0.74-3.87$, $P=0.22$; 24-month, RR 0.60, 95\% CI 0.33-1.10, $P=0.10$ ). While the pooled analysis of five trials conducted in China indicated a significant increase in 6-month and 12-month survival in octreotide-treated patients compared with controls (6-month, RR 1.78, 95\% CI 1.25-2.52, $P=0.001$; 12-month, RR $4.59,95 \%$ CI 1.99-10.59, $P=0.0003)$. The 24-month survival rate was also higher in the octreotide group, but the difference was not significant (RR 7.32, 95\% CI 0.92-58.14, $P=0.06$ ) (Ji et al. 2011). This suggests that octreotide may prolong survival in patients with advanced HCC, although the effect appears to be limited to nonWestern populations. The predictive role of SSTR expression was not investigated in this meta-analysis, as it was reported only in one study (Dimitroulopoulos et al. 2007) and needs to be addressed in future studies as discussed earlier.

In a different setting, Jia et al. evaluated in a nonrandomised study whether post-transcatheter arterial chemoembolisation (TACE) combination therapy with unfractionated heparin (1250-2500 U) and octreotide influences development of extrahepatic disease. A total of 147 patients diagnosed with HCC suitable for TACE were enrolled, received 2-4 TACE procedures, and were monitored for 1 year. Of these, 84 received the heparin plus octreotide combination treatment and 63 patients received heparin alone (control group). They found a significant decrease in the incidence of tumour metastasis in patients receiving the combination treatment postTACE with no significant toxic or adverse effects (Jia et al. 2012); however, the non-randomised nature of this study limits the conclusions that can be drawn. Once again, SSTR expression was not evaluated.

In conclusion, the available data concerning SSAs for tumour control in advanced HCC are insufficient to draw firm evidence-based conclusions and further evaluation of this issue seems to be of value. Moreover, the role of SSAs in HCC subsets such as those with high SSTR expression warrants investigation in prospective studies.

\section{Novel approaches for optimising SSTR targeting in HCC}

\section{Pretreatment assessment of SSTRs through nuclear medicine studies}

Two studies have demonstrated the feasibility of scintigraphy to detect SSTRs in advanced HCC using either ${ }^{68} \mathrm{Ga}$-DOTATOC PET (Freesmeyer et al. 2009) or $\left({ }^{99} \mathrm{~m}\right.$ )TcHYNIC-Tyr(3)-octreotide in human HCC-bearing nude mice (Li et al. 2005). Additionally, in a multicentre French study, the feasibility of SSTR screening using ${ }^{111}$ indium pentetreotide in advanced HCC before SSA treatment was evaluated. This study demonstrated SSTR scintigraphic uptake in $36 \%$ of primary tumours and $41 \%$ of metastatic sites (Nguyen-Khac et al. 2009).

Dimitroulopoulos et al. conducted a randomised controlled trial evaluating long-acting octreotide monotherapy in the treatment of patients with advanced HCC and scintigraphic evidence of ${ }^{111}$ indium octreotide accumulation. In this study, a total of 127 cirrhotic patients, stages

Published by Bioscientifica Ltd 
A-B, due to chronic viral infections and with advanced HCC, were enrolled. Scintigraphy with ${ }^{111}$ indium-labelled octreotide was performed in all cases. Patients with increased isotope accumulation were randomised to receive either oral placebo only or octreotide/octreotide LAR only as follows: octreotide $0.5 \mathrm{mg}$ s.c. every $8 \mathrm{~h}$ for 6 weeks; octreotide LAR $20 \mathrm{mg}$ i.m. at the end of weeks $4-8$ and octreotide LAR $30 \mathrm{mg}$ i.m. at the end of week 12 and every 4 weeks, with monthly follow-up and estimation of the quality of life (using the QLQ-C30 questionnaire). Patients with negative SSTR detection were followed up in the same manner. Scintigraphy demonstrated the presence of SSTRs in 61 patients. Thirty were randomised to receive only placebo and 31 only octreotide. A significantly higher survival time was observed for the octreotide-treated group ( $49 \pm 6$ weeks) compared with the control group ( $28 \pm 1$ weeks) and to the SSTR-negative group ( $28 \pm 2$ weeks), $P<0.01$ (Dimitroulopoulos et al. 2007).

However, the published data with regard to the use of scintigraphy as a prognostic marker in HCC patients treated with SSAs or to predict the benefit from SSA therapy are not consistent. For example, in a study conducted in 63 advanced HCC patients treated with long-acting octreotide, positive scintigraphy was noted in $34(56 \%)$ patients, but there was no relationship with tumour response or the quality of life (Cebon et al. 2006). This discrepancy in the predictive value of octreotide scintigraphy to guide therapeutic decision making needs to be further evaluated in larger randomised prospective controlled studies.

\section{Assessment of predictive serum and tissue biomarkers in patients receiving SSAs}

Montella et al. have evaluated the predictive role of VEGF in a cohort of HCC patients receiving octreotide monotherapy. They found a statistically significant positive correlation between increases in serum VEGF levels during octreotide therapy and tumour progression (Montella et al. 2008).

\section{Optimising drug delivery of SSAs}

Zhang et al. have evaluated the treatment of liver cancer in mice by the intratumoural injection of an octreotidebased temperature-sensitive gel (OCT-P407). Tumours were injected with OCT-P407 or standard octreotide solution and intratumoural octreotide levels were subsequently measured by HPLC over a specific time period. OCT-P407 maintained an effective intratumoural octreotide concentration for a longer period than standard octreotide and hence may potentially deliver a greater therapeutic effect, although the feasibility of intratumoural drug delivery in humans is unclear (Zhang et al. 2014).

\section{Ongoing studies}

Two ongoing clinical trials are investigating therapy with SSAs in HCC patients (www.clinicaltrials.gov; last accessed 1st June 2014). Both studies are targeting unselected population with respect to SSTR expression.

- Phase II trial of pasireotide (an SSA with a broader and more potent affinity, starting at a dose of $60 \mathrm{mg}$ via i.m. injection, every 28 days) in patients with unresectable HCC (after progression with sorafenib) (NCT01639352). This trial is currently recruiting patients (planned sample size: 30 patients). The primary end point is disease control rate (complete response, partial response or stable disease). Secondary outcomes will include PFS, OS, response rate (complete or partial) and duration of response and adverse events.

- Another phase II trial, also with pasireotide $(60 \mathrm{mg}$ administered by i.m. injection once in 28 days) and with everolimus (an orally available mTOR inhibitor) $(7.5 \mathrm{mg}$ administered daily for 28 days), in patients with advanced or metastatic HCC (NCT01488487) intolerant to systemic treatment with sorafenib. This trial has completed recruitment $(n=30)$. The primary end point is time to progression based on modified HCC RECIST criteria (radiological progression in a previously embolised lobe, development of new lesions in an untreated lobe or evidence of extrahepatic progression). Secondary outcomes will include toxicity, OS and response rate (complete or partial).

Data from these studies will provide the efficacy for patients with advanced HCC; however, the role of SSTR expression and appropriateness for using this as a biomarker predictive of response remain unanswered.

\section{Conclusions and future directions}

SSTRs have been extensively studied in preclinical and clinical settings of HCC. With the development of different SSTR-targeted agents, SSTR expression became relevant in terms of anti-tumour efficacy prompting clinical investigation of SSAs in advanced HCC. The available data concerning SSAs for tumour control in advanced HCC are insufficient to draw firm evidence-based conclusions, and further evaluation of this issue seems to be of value. The use of potential biomarkers, including SSTR expression profiling by IHC and scintigraphy, to

Published by Bioscientifica Ltd. 
select patients for SSA-based therapy is supported by some preclinical and clinical data, but needs to be further investigated in large prospective studies.

The highly varied aetiology and natural history of HCC implies a similarly heterogeneous array of molecular genetic abnormalities. The development of a robust molecular classification system to define the more common aberrations in HCC should present new potential biomarkers and opportunities for personalisation of therapy in HCC, and it seems likely that SSTRs may have a role to play in this process.

\section{Declaration of interest}

The authors declare that there is no conflict of interest that could be perceived as prejudicing the impartiality of the review.

\section{Funding}

This research did not receive any specific grant from any funding agency in the public, commercial or not-for-profit sector.

\section{References}

Bajetta E, Procopio G, Ferrari L, Martinetti A, Zilembo N, Catena L, Alu M, Della TS, Alberti D \& Buzzoni R 2002 A randomized, multicenter prospective trial assessing long-acting release octreotide pamoate plus tamoxifen as a first line therapy for advanced breast carcinoma. Cancer 94 299-304. (doi:10.1002/cncr.10239)

Barbare JC, Bouche O, Bonnetain F, Dahan L, Lombard-Bohas C, Faroux R, Raoul JL, Cattan S, Lemoine A, Blanc JF et al. 2009 Treatment of advanced hepatocellular carcinoma with long-acting octreotide: a phase III multicentre, randomised, double blind placebo-controlled study. European Journal of Cancer 45 1788-1797. (doi:10.1016/j.ejca.2009.02.018)

Barbieri F, Bajetto A, Pattarozzi A, Gatti M, Wurth R, Thellung S, Corsaro A, Villa V, Nizzari M \& Florio T 2013 Peptide receptor targeting in cancer: the somatostatin paradigm. International Journal of Peptides $\mathbf{2 0 1 3}$ 926295. (doi:10.1155/2013/926295)

Becker G, Allgaier HP, Olschewski M, Zahringer A \& Blum HE 2007 Longacting octreotide versus placebo for treatment of advanced HCC: a randomized controlled double-blind study. Hepatology 45 9-15. (doi:10.1002/hep.21468)

Benoit R, Esch F, Bennett HP, Ling N, Ravazzola M, Orci L \& Mufson EJ 1990 Processing of prosomatostatin. Metabolism 39 22-25. (doi:10.1016/ 0026-0495(90)90202-N)

Blaker M, Schmitz M, Gocht A, Burghardt S, Schulz M, Broring DC, Pace A, Greten H \& De Weerth A 2004 Differential expression of somatostatin receptor subtypes in hepatocellular carcinomas. Journal of Hepatology $\mathbf{4 1}$ 112-118. (doi:10.1016/j.jhep.2004.03.018)

Borbath I, Lhommel R, Guiot Y, Coche E \& Sempoux C 2012 Lanreotide treatment of metastatic hepatocellular carcinoma resulting in partial regression and more than 3 years of progression-free survival. Acta Gastroenterologica Belgica 75 270-273.

Caplin M 2014 Progression-free survival (PFS) with lanreotide autogel/ depot (LAN) in enteropancreatic NETs patients: the CLARINET extension study. ASCO 2014 Annual Meeting. Journal of Clinical Oncology 32 (May 20 Supplement) abstract 4107.

Cebon J, Findlay M, Hargreaves C, Stockler M, Thompson P, Boyer M, Roberts S, Poon A, Scott AM, Kalff V et al. 2006 Somatostatin receptor expression, tumour response, and quality of life in patients with advanced hepatocellular carcinoma treated with long-acting octreotide. British Journal of Cancer 95 853-861. (doi:10.1038/sj.bjc.6603325)

Chen X, Liu Z \& Ai Z 2001 Antineoplastic mechanism of Octreotide action in human hepatoma. Chinese Medical Journal 114 1167-1170.

Chen JD, Xiong YQ, Dong K, Luo J, Yue LX \& Chen Q 2014 Clinical significance of joint detection of serum VEGF, SIL-2R and HGF in patients with primary hepatocellular carcinoma before and after percutaneous microwave coagulation therapy. Asian Pacific Journal of Cancer Prevention 15 4545-4548. (doi:10.7314/APJCP.2014.15.11.4545)

Cheng AL, Kang YK, Chen Z, Tsao CJ, Qin S, Kim JS, Luo R, Feng J, Ye S, Yang TS et al. 2009 Efficacy and safety of sorafenib in patients in the Asia-Pacific region with advanced hepatocellular carcinoma: a phase III randomised, double-blind, placebo-controlled trial. Lancet Oncology 10 25-34. (doi:10.1016/S1470-2045(08)70285-7)

Chou CK, Ho LT, Ting LP, Hu CP, Su TS, Chang WC, Suen CS, Huang MY \& Chang CM 1987 Selective suppression of insulin-induced proliferation of cultured human hepatoma cells by somatostatin. Journal of Clinical Investigation 79 175-178. (doi:10.1172/JCI112780)

Dasgupta P 2004 Somatostatin analogues: multiple roles in cellular proliferation, neoplasia, and angiogenesis. Pharmacology \& Therapeutics 102 61-85. (doi:10.1016/j.pharmthera.2004.02.002)

Dimitroulopoulos D, Xinopoulos D, Tsamakidis K, Zisimopoulos A, Andriotis E, Panagiotakos D, Fotopoulou A, Chrysohoou C, Bazinis A, Daskalopoulou D et al. 2007 Long acting octreotide in the treatment of advanced hepatocellular cancer and overexpression of somatostatin receptors: randomized placebo-controlled trial. World Journal of Gastroenterology 13 3164-3170. (doi:10.3748/wjg.v13.i23.3164)

Freesmeyer M, Schulz S, Knosel T \& Settmacher U 2009 Imaging of somatostatin receptor subtype 2 in advanced hepatocellular carcinoma by 68Ga-DOTATOC PET. Nuklearmedizin 48 N17-N18.

Galuppo R, Maynard E, Shah M, Daily MF, Chen C, Spear BT \& Gedaly R 2014 Synergistic inhibition of HCC and liver cancer stem cell proliferation by targeting RAS/RAF/MAPK and WNT/ $\beta$-catenin pathways. Anticancer Research 34 1709-1713.

Garcia de la Torre N, Wass JA \& Turner HE 2002 Antiangiogenic effects of somatostatin analogues. Clinical Endocrinology 57 425-441. (doi:10.1046/j.1365-2265.2002.01619.x)

Goldberg RM, Moertel CG, Wieand HS, Krook JE, Schutt AJ, Veeder MH, Mailliard JA \& Dalton RJ 1995 A phase III evaluation of a somatostatin analogue (octreotide) in the treatment of patients with asymptomatic advanced colon carcinoma. North Central Cancer Treatment Group and the Mayo Clinic. Cancer 76 961-966. (doi:10.1002/10970142(19950915)76:6<961::AID-CNCR2820760608>3.0.CO;2-A)

Hejna M, Schmidinger M \& Raderer M 2002 The clinical role of somatostatin analogues as antineoplastic agents: much ado about nothing? Annals of Oncology 13 653-668. (doi:10.1093/annonc/mdf142)

Hua YP, Huang JF, Liang LJ, Li SQ, Lai JM \& Liang HZ 2005 The study of inhibition effect of octreotide on the growth of hepatocellular carcinoma xenografts in situ in nude mice. Zhonghua Wai Ke Za Zhi 43 721-725.

Ingle JN, Suman VJ, Kardinal CG, Krook JE, Mailliard JA, Veeder MH, Loprinzi CL, Dalton RJ, Hartmann LC, Conover CA et al. 1999 A randomized trial of tamoxifen alone or combined with octreotide in the treatment of women with metastatic breast carcinoma. Cancer 85 1284-1292. (doi:10.1002/ (SICI)1097-0142(19990315)85:6 < 1284::AID-CNCR10>3.0.CO;2-P)

Ji XQ, Ruan XJ, Chen H, Chen G, Li SY \& Yu B 2011 Somatostatin analogues in advanced hepatocellular carcinoma: an updated systematic review and meta-analysis of randomized controlled trials. Medical Science Monitor 17 RA169-RA176. (doi:10.12659/MSM.881892)

Jia WD, Xu GL, Wang W, Wang ZH, Li JS, Ma JL, Ren WH, Ge YS, Yu JH \& Liu WB 2009 A somatostatin analogue, octreotide, inhibits the occurrence of second primary tumors and lung metastasis after resection of hepatocellular carcinoma in mice. Tohoku Journal of Experimental Medicine 218 155-160. (doi:10.1620/tjem.218.155)

Jia W, Feng K, Fan P, Fan G, Yang S, Zhang T, Wei Q \& Qian L 2012 Post-TACE combination therapy of heparin and octreotide results in 
decreased tumor metastasis in extrahepatic tumorigenesis. Cell Biochemistry and Biophysics 62 35-40. (doi:10.1007/s12013-011-9255-8)

Keskin O \& Yalcin S 2013 A review of the use of somatostatin analogs in oncology. OncoTargets and Therapy 6 471-483. (doi:10.2147/OTT.S39987)

Kim DY \& Han KH 2012 Epidemiology and surveillance of hepatocellular carcinoma. Liver Cancer 1 2-14. (doi:10.1159/000339016)

Koc EU, Ozgur T, Yerci O \& Gurel S 2013 Somatostatin receptor 1 (SSTR1) and somatostatin receptor 5 (SSTR5) expression in hepatocellular carcinoma. Hepatogastroenterology 60 1693-1697.

Kouroumalis E, Skordilis P, Thermos K, Vasilaki A, Moschandrea J \& Manousos ON 1998 Treatment of hepatocellular carcinoma with octreotide: a randomised controlled study. Gut $\mathbf{4 2} 442-447$ (doi:10.1136/gut.42.3.442)

Krulich L, Dhariwal AP \& McCann SM 1968 Stimulatory and inhibitory effects of purified hypothalamic extracts on growth hormone release from rat pituitary in vitro. Endocrinology 83 783-790. (doi:10.1210/ endo-83-4-783)

Lamberts SW, van der Lely AJ, de Herder WW \& Hofland LJ 1996 Octreotide. New England Journal of Medicine 334 246-254. (doi:10.1056/ NEJM199601253340408

Li Y, Si JM, Zhang J, Du J, Wang F \& Jia B 2005 Somatostatin receptor subtype 2-mediated scintigraphy and localization using (99m)TcHYNIC-Tyr(3)-octreotide in human hepatocellular carcinoma-bearing nude mice. World Journal of Gastroenterology 11 3953-3957.

Li S, Liu Y \& Shen Z 2012 Characterization of somatostatin receptor 2 and 5 expression in operable hepatocellular carcinomas. Hepatogastroenterology 59 2054-2058. (doi:10.5754/hge11217)

Liu HL, Huo L \& Wang L 2004 Octreotide inhibits proliferation and induces apoptosis of hepatocellular carcinoma cells. Acta Pharmacologica Sinica 25 1380-1386.

Liu Y, Jiang L \& Mu Y 2013 Somatostatin receptor subtypes 2 and 5 are associated with better survival in operable hepatitis B-related hepatocellular carcinoma following octreotide long-acting release treatment. Oncology Letters 6 821-828. (doi:10.3892/ol.2013.1435)

Llovet JM, Ricci S, Mazzaferro V, Hilgard P, Gane E, Blanc JF, de Oliveira AC, Santoro A, Raoul JL, Forner A et al. 2008 Sorafenib in advanced hepatocellular carcinoma. New England Journal of Medicine 359 378-390. (doi:10.1056/NEJMoa0708857)

Montella L, Addeo R, Caraglia M, Faiola V, Guarrasi R, Vincenzi B, Palmeri A, Capasso E, Nocera V, Tarantino L et al. 2008 Vascular endothelial growth factor monitoring in advanced hepatocellular carcinoma patients treated with radiofrequency ablation plus octreotide: a single center experience. Oncology Reports 20 385-390. (doi:10.3892/or_00000019)

Nguyen-Khac E, Ollivier I, Aparicio T, Moullart V, Hugentobler A, Lebtahi R, Lobry C, Susini C, Duhamel C, Hommel S et al. 2009 Somatostatin receptor scintigraphy screening in advanced hepatocarcinoma: a multicenter French study. Cancer Biology \& Therapy 8 2033-2039. (doi:10.4161/cbt.8.21.9737)

Park JW, Amarapurkar D, Chao Y, Chen PJ, Geschwind JF, Goh KL, Han KH, Kudo M, Lee HC, Lee RC et al. 2013 Consensus recommendations and review by an International Expert Panel on Interventions in Hepatocellular Carcinoma (EPOIHCC). Liver International 33 327-337. (doi:10.1111/liv.12083)

Parkin DM, Bray F, Ferlay J \& Pisani P 2005 Global cancer statistics, 2002. CA: A Cancer Journal for Clinicians 55 74-108. (doi:10.3322/canjclin.55.2.74)

Plentz RR, Tillmann HL, Kubicka S, Bleck JS, Gebel M, Manns MP \& Rudolph KL 2005 Hepatocellular carcinoma and octreotide: treatment results in prospectively assigned patients with advanced tumor and cirrhosis stage. Journal of Gastroenterology and Hepatology 20 1422-1428. (doi:10.1111/j.1440-1746.2005.03959.x)
Prete SD, Montella L, Caraglia M, Maiorino L, Cennamo G, Montesarchio V, Piai G, Febbraro A, Tarantino L, Capasso E et al. 2010 Sorafenib plus octreotide is an effective and safe treatment in advanced hepatocellular carcinoma: multicenter phase II So.LAR. study. Cancer Chemotherapy and Pharmacology 66 837-844. (doi:10.1007/s00280-009-1226-z)

Raderer M, Hejna MH, Muller C, Kornek GV, Kurtaran A, Virgolini I \& Scheithauer WE 2000 Treatment of hepatocellular cancer with the long acting somatostatin analog lanreotide in vitro and in vivo. International Journal of Oncology 16 1197-1398. (doi:10.3892/ijo.16.6.1197)

Reynaert H, Rombouts K, Vandermonde A, Urbain D, Kumar U, Bioulac-Sage P, Pinzani M, Rosenbaum J \& Geerts A 2004 Expression of somatostatin receptors in normal and cirrhotic human liver and in hepatocellular carcinoma. Gut 53 1180-1189. (doi:10.1136/gut.2003.036053)

Rinke A, Muller HH, Schade-Brittinger C, Klose KJ, Barth P, Wied M, Mayer C, Aminossadati B, Pape UF, Blaker M et al. 2009 Placebo-controlled, doubleblind, prospective, randomized study on the effect of octreotide LAR in the control of tumor growth in patients with metastatic neuroendocrine midgut tumors: a report from the PROMID Study Group. Journal of Clinical Oncology 27 4656-4663. (doi:10.1200/JCO.2009.22.8510)

Ristori C, Ferretti ME, Pavan B, Cervellati F, Casini G, Catalani E, Dal Monte M \& Biondi C 2008 Adenylyl cyclase/cAMP system involvement in the antiangiogenic effect of somatostatin in the retina. Results from transgenic mice. Neurochemical Research 33 1247-1255. (doi:10.1007/s11064-007-9576-6)

Samonakis DN, Moschandreas J, Arnaoutis T, Skordilis P, Leontidis C, Vafiades I \& Kouroumalis E 2002 Treatment of hepatocellular carcinoma with long acting somatostatin analogues. Oncology Reports 9 903-907. (doi:10.3892/or.9.4.903v)

Schoniger-Hekele M, Kettenbach J, Peck-Radosavljevic M \& Muller C 2009 Octreotide treatment of patients with hepatocellular carcinoma - a retrospective single centre controlled study. Journal of Experimental \& Clinical Cancer Research 28 142. (doi:10.1186/1756-9966-28-142)

Shah U, O’Neil B, Allen J, Goldberg RM, Bernard S, Moore D, Venook AP \& Morse MM 2009 A phase II study of long-acting octreotide in patients with advanced hepatocellular carcinoma and CLIP score of 3 or higher. Gastrointestinal Cancer Research 3 45-48.

Song DS \& Bae SH 2012 Changes of guidelines diagnosing hepatocellular carcinoma during the last ten-year period. Clinical and Molecular Hepatology 18 258-267. (doi:10.3350/cmh.2012.18.3.258)

Treiber G, Rocken C, Wex T \& Malfertheiner P 2007 Octreotide alone or in combination with rofecoxib as palliative treatment for advanced hepatocellular cancer. Zeitschrift für Gastroenterologie 45 369-377.

Verhoef C, van Dekken H, Hofland LJ, Zondervan PE, de Wilt JH, van Marion R, de Man RA, IJzermans JN \& van Eijck CH 2008 Somatostatin receptor in human hepatocellular carcinomas: biological, patient and tumor characteristics. Digestive Surgery 25 21-26. (doi:10.1159/000117819)

Verset G, Verslype C, Reynaert H, Borbath I, Langlet P, Vandebroek A, Peeters M, Houbiers G, Francque S, Arvanitakis M et al. 2007 Efficacy of the combination of long-acting release octreotide and tamoxifen in patients with advanced hepatocellular carcinoma: a randomised multicentre phase III study. British Journal of Cancer 97 582-588. (doi:10.1038/sj.bjc.6603901)

Yuen MF, Poon RT, Lai CL, Fan ST, Lo CM, Wong KW, Wong WM \& Wong BC 2002 A randomized placebo-controlled study of long-acting octreotide for the treatment of advanced hepatocellular carcinoma. Hepatology 36 687-691. (doi:10.1053/jhep.2002.35071)

Zhang L, Yu S, Duan Z, Wang Q, Tian G, Tian Y, Zhao W, Wang H, Zhang C, Guo $S$ et al. 2014 Treatment of liver cancer in mice by the intratumoral injection of an octreotide-based temperature-sensitive gel. International Journal of Molecular Medicine 33 117-127. (doi:10.3892/ijmm.2013.1542)

Received in final form 13 October 2014

Accepted 21 October 2014

Made available online as an Accepted Preprint

21 October 2014 http://erc.endocrinology-journals.org

DOI: 10.1530/ERC-14-0389
(C) 2014 Society for Endocrinology Printed in Great Britain
Published by Bioscientifica Ltd 